\title{
Designing Instruction to Improve Lifelong Inquiry Learning
}

\author{
Marcia C. Linn \\ University of California Berkeley, USA \\ Bat-Sheva Eylon \\ Weirmann Institute of Science, ISRAEL \\ Anna Rafferty \\ Carleton College, USA \\ Jonathan M. Vitale \\ University of California Berkeley, USA
}

Received 10 September 2014; accepted 23 December 2014; published 25 March 2015

\begin{abstract}
Citizens need the capability to conduct their own inquiry projects so that they can make sense of claims about new energy policies, health remedies, or financial opportunities. To develop the lifelong capability to grapple with these dilemmas, we report on ways to design precollege units that engage students in realistic, personally relevant investigations. Our investigations and syntheses of related work have resulted in the knowledge integration framework. This constructivist framework shows that, to succeed, learners build on what they know and use reasoning strategies to make sense of new information. To help designers we have identified a pattern that can guide instructional designers. The pattern involves supporting students to articulate their existing ideas, add new, normative ideas, distinguish them from their existing ideas, and reflect on their experiences as they increase the coherence of their ideas. To guide students, we are currently investigating automated guidance based on analysis of natural language essays students write while investigating complex problems such as global climate change.
\end{abstract}

Keywords: inquiry learning; knowledge integration, computer-supported learning, science education, lifelong

\section{DESIGNING INSTRUCTION TO IMPROVE LIFELONG INQUIRY LEARNING}

Citizens need the capability to conduct their own inquiry projects so that they can make sense of claims about new energy policies, health remedies, or financial opportunities. This involves interpreting new scientific evidence concerning contemporary dilemmas such as climate change, cancer treatment, and airbag safety. To develop the lifelong capability to grapple with these

Correspondence to: Marcia C. Linn,

UC Berkeley Graduate School of Education, 4611

Tolman Hall, mc1670, Berkeley, CA 94720,

USA.

Email: mclinn@berkeley.edu

doi: 10.12973/eurasia.2015.1317a dilemmas, we report on research that illustrates ways to design precollege units that engage students in realistic, personally relevant investigations and strategies for guiding students that prepare them to deal with future dilemmas. This research builds on our synthesis of research comparing alternative ways to design instruction that resulted in the knowledge integration framework (Linn \& Eylon, 2011). By knowledge integration we refer to the process of articulating ideas, adding new ideas, distinguishing among alternative explanations using scientific evidence, and building coherent understanding by reflecting on the relationships between ideas and evidence.

Our research is conducted using the Web-based Inquiry Science Environment (WISE), an online authoring and instructional delivery system that includes features designed to promote knowledge integration 


\section{State of the literature}

- Curriculum designers and researchers are looking for guidelines and design principles to speed up the creation of science inquiry activities.

- Guiding students when they get stuck, head down a wrong path, or develop scientifically inaccurate ideas challenges teachers who implement individualized inquiry activities in classrooms.

- Teachers can improve student outcomes when they provide hints rather than telling students the right answer but they rarely have time to guide each student doing an inquiry project.

\section{Contribution of this paper to the literature}

- Knowledge integration design principles and patterns offer designers a head start on creating effective inquiry activities.

- By using natural language processing to score essays and the Web-based Inquiry Science Environment to use the scores to assign guidance, technology can serve as an inquiry partner to enhance the impact of the teacher.

- When teacher guidance and WISE inquiry guidance are combined, students benefit.

(Donnelly, Linn, \& Ludvigsen, 2014). WISE activities help students integrate ideas about complex science topics while also developing lifelong learning skills (Chiu \& Linn, 2013; Slotta \& Linn, 2010). WISE is free and available to teachers and researchers everywhere. Units are available in English, Mandarin, Spanish, and other languages. See http://WISE.Berkeley.edu. In this paper we describe the process of designing instruction for knowledge integration and we report on new research exploring ways to automatically analyze student responses and generate personalized guidance that improves the coherence of the response.

\section{DESIGN FOR KNOWLEDGE INTEGRATION}

Our investigations and syntheses of related work have resulted in a constructivist framework we call knowledge integration. This framework shows that, to succeed, learners build on what they know and use reasoning strategies to make sense of new information. Syntheses of many research studies enabled us to identify a pattern that can guide instructional designers. The pattern involves supporting students to articulate their existing ideas, add new, normative ideas, distinguish them from their existing ideas, and reflect on their experiences as they increase the coherence of their ideas. The pattern takes advantage of the repertoire of ideas students have developed about any scientific topic. This repertoire results from everyday experience, efforts to explain the natural world, varied sources of information, and formal instruction. The knowledge integration framework helps students build on and sort out these ideas to improve the accuracy and coherence of their views. A broad range of research supports the value of designing scaffolds that engage students in following this framework (Linn \& Eylon, 2011; Quintana et al., 2006). The pattern is composed of four processes: eliciting ideas, adding ideas, distinguishing among ideas, and reflecting on ideas. We discuss each of these processes in turn, focusing on how each process contributes to building a cohesive understanding.

\section{Eliciting Ideas}

When students are asked to articulate their existing ideas, they reveal to themselves and their teachers the current understanding that they have developed about the topic. Students are likely to hold a diverse set of often contradictory ideas about a scientific topic. Students hold ideas that they can build on to understand the topic as well as ideas that should be distinguished from normative ideas to achieve deep understanding. By eliciting these ideas we give students the opportunity to consider them as they add new ideas and distinguish new and existing ideas. A particularly effective way for elciting ideas is to ask students to make predictions. Many research studies have shown that when students make predictions they are more likely to learn the material than when they do not make predictions (Linn \& Songer, 1991; Mayer, Dow, and Mayer, 2003; White \& Gunstone, 1992).

Middle school students hold a number of seemingly inconsistent ideas about the causes of climate change (Andersson \& Wallin, 2000; Boyes \& Stanisstreet 1997; Shepardson, Niyogi, Choi \& Charusombat, 2009). Students may confuse multiple atmospheric concepts, believing that climate change is caused by ozone layer depletion, or that greenhouse gases are stored in a single layer and act like a "blanket". Students may believe that climate change is caused by all sources of pollution, such as smog, exhaust from cars and factories, and littering (Svihla \& Linn, 2012). Among these ideas, each student is likely to have ideas stemming from relevant personal experiences that may be leveraged for instruction. For example, most have experienced getting into a hot car that has been resting in direct sunlight. Scaffolding students to see personal experiences as relevant to the greenhouse effect could lead to better understanding. In addition, students may advocate for general remedies, such as planting trees, without appreciating the rationale for them. Providing an opportunity for students to build on their own ideas while constructing a normative understanding of the mechanisms of climate change has two benefits. First, it enables students to see the value in their own efforts to 
interpret their experiences. Second, it ensures that students establish their own view before viewing the ideas of experts.

Yet, for students to fully understand the normative mechanisms related to a science topic, they need to distinguish normative ideas from their other beliefs that may be inappropriate or play only a minor role in the phenomenon. When students do not have the opportunity to distinguish among their ideas, they often revert back to their original ideas when confronted with a complex dilemma. For example, in a recent study of climate change many students made progress in understanding the role of greenhouse gases but when they encountered a challenging problem they returned to their initial (and irrelevant) ideas about ozone (Visintainer \& Linn, submitted). Likewise, while some students validly argued for the role of greenhouse gas emissions from cars in climate change, they also argued that the exhaust emitted from cars plays a role because it is hot. Eliciting the ideas students generate on their own early in instruction provides an opportunity for students to compare them to the new ideas and make appropriate distinctions and for teachers to gear instruction to the beliefs of their students.

\section{Adding ideas}

To add normative ideas, knowledge integration researchers have sought ways to take advantage of technology by designing visualizations of scientific phenomena. Visualizations can help students get insights into things that are too small, vast, or complex to observe directly. They can support students to conduct virtual experiments and identify valid inferences (deJong, Linn, \& Zacharia, 2013; McElhaney \& Linn, 2011). Dynamic visualizations, when well designed, are more effective than static images (Ryoo \& Linn, 2012). In particular, for photosynthesis, where energy transformations are crucial to understanding, a dynamic visualization provides an intuitive means of conveying when and how energy is transformed. WISE curriculum units consistently incorporate dynamic visualizations to depict motion, energy flow, energy transformation, and related concepts.

In another example, for a unit on thermodynamics, some students think that when a hot object touches a cold object, that atoms or molecules transfer between the objects (Chang \& Linn, 2013). The students may not have the idea that energy, in the form of molecular movement, transfers continuously from the hotter object to the colder object. In a WISE unit called Thermal Equilibrium students explore this phenomenon with a visualization of a cup of hot coffee placed on a room temperature counter. The visualization depicts heat transfer between the cup and counter at the molecular level. By exploring the visualization students add the idea that changes occur in the rate of movement of the molecules rather than the actual mixing of the molecules or atoms. This visualization helps students add new ideas. They still need opportunities to distinguish ideas to sort out their diverse views.

\section{Distinguishing among ideas}

Adding accurate ideas is not sufficient to ensure that students understand scientific phenomena. Students need to distinguish among their own diverse ideas as well as the new ideas using evidence from experiments, observations, or other sources. Without distinguishing these ideas, students may develop a collection of multiple, potentially contradictory and disconnected ideas. WISE units guide students to develop criteria that allow them to select the most valid ideas from among their repertoire. We have designed a variety of guidance tools, including automated guidance, to help students distinguish ideas. We provide several examples.

For the WISE unit called Global Climate Change we designed an interactive visualization to both add ideas and help students distinguish ideas about the role of $\mathrm{CO} 2$. The visualization featured virtual experiments implemented using NetLogo (see Figure 1). In a series of experiments, students investigate the factors leading to accumulation of greenhouse gases such as the impact of changes in albedo or increases in release of greenhouse gases by factories and cars. These investigations allow students to add ideas based on their observations. By addressing a consistent theme of climate change through a procession of visualizations students have the opportunity to distinguish among their ideas in multiple contexts.

In the case of the Thermal Equilibrium unit discussed above, visualizations not only serve as an opportunity to discover new ideas, but as an experimental context for comparing ideas. When students spontaneously use the simulations to "vary one thing at a time," they are distinguishing among their ideas. Varma and Linn (2012) asked students to explore albedo, clouds and greenhouse gases in the WISE Global Climate Change unit. While students had the opportunity to explore multiple ideas in each simulation, those students who applied a "vary one thing at a time" strategy reached more valid conclusions than those who applied a more haphazard approach.

Subsequent investigations have explored ways to scaffold students to investigate the visualizations and also added activities to support specific mechanisms leading to the production of greenhouse gases. Scaffolds include framing goals for exploration (e.g. "try comparing a low level of albedo to a high level"), providing meaningful follow-up tasks, or redirecting students back to the visualization if they need further information. For example, in Thermal Equilibrium 


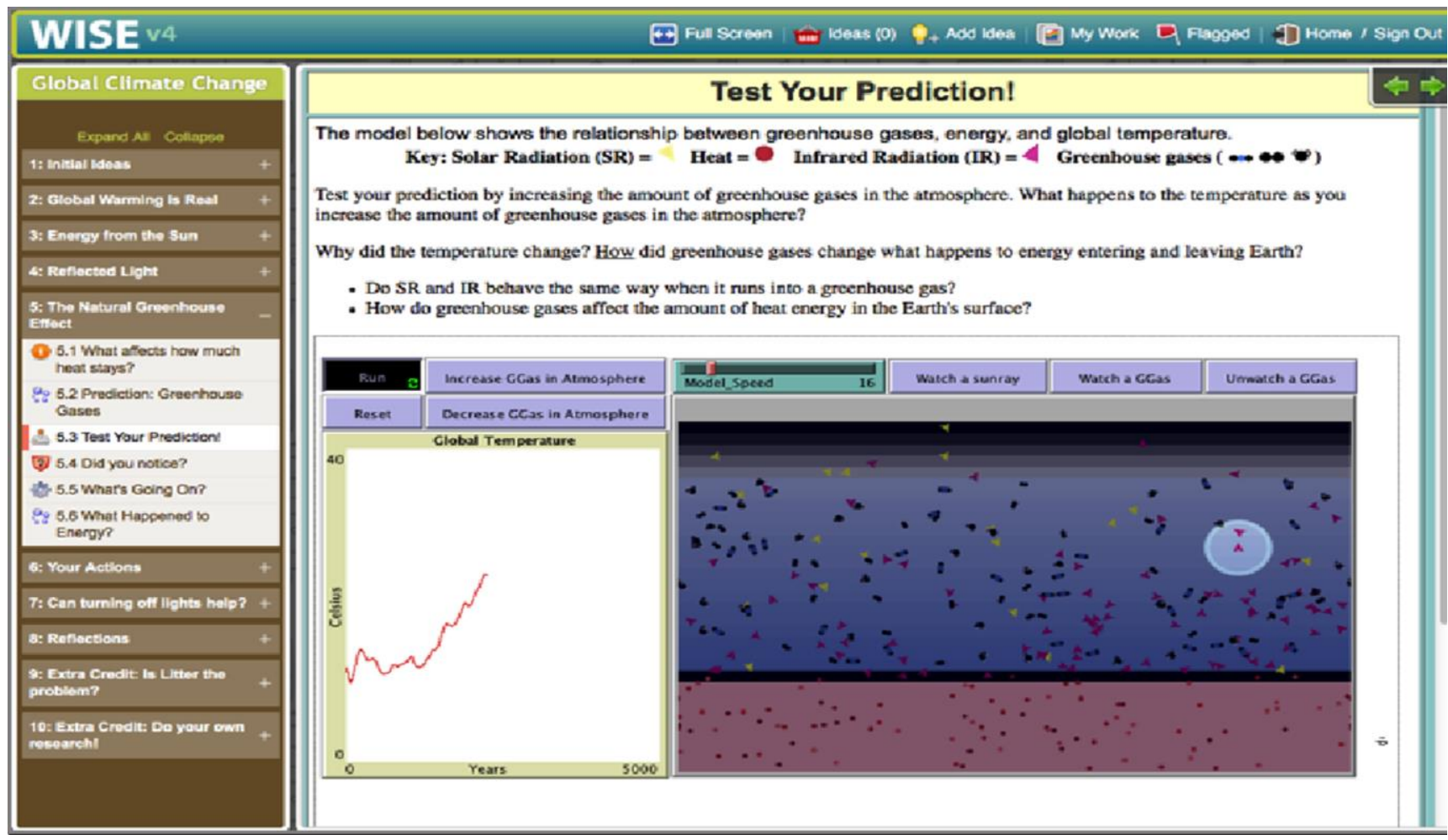

\section{WISEv4}

\begin{tabular}{|c|c|}
\hline \multicolumn{2}{|c|}{ Global Climate Chang: } \\
\hline Expand Al Collpas & \\
\hline | 1 :Inldinl ldeas & + \\
\hline | z= Global Wharming is Real & + \\
\hline 3: Energy from the Sun & + \\
\hline 4: Reflected Lbght & + \\
\hline $\begin{array}{l}\text { S5 The Nuturat Greenhoubse } \\
\text { Entect }\end{array}$ & + \\
\hline C: Your Actions & + \\
\hline $\begin{array}{l}\text { 7: Can turning off lights } \\
\text { help? }\end{array}$ & \\
\hline $\begin{array}{l}\text { 8) } 7,1 \text { Predict wask va. } \\
\text { Electricity }\end{array}$ & \\
\hline $\begin{array}{l}27.2 \text { Driving vas, Electricity } \\
\text { Model }\end{array}$ & \\
\hline (7) 7.3 Was Dnving Worse? & \\
\hline $\begin{array}{l}\text { A } 7.4 \text { Fues, Eectrioty, and } \\
\text { Carbon Diloxide }\end{array}$ & \\
\hline $\begin{array}{l}99.5 \text { Pot Aovise Owan - } \\
\text { Lyms }\end{array}$ & \\
\hline A: Ranfoctlons & + \\
\hline 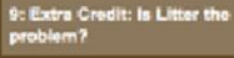 & + \\
\hline $\begin{array}{l}\text { 10: Entra Credit: Do your } \\
\text { own resesurehl }\end{array}$ & + \\
\hline
\end{tabular}

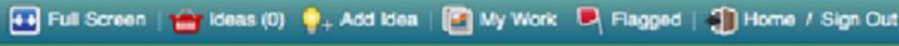

The Greenhouse Effect and You

How do I contribute to the greenhouse effect?

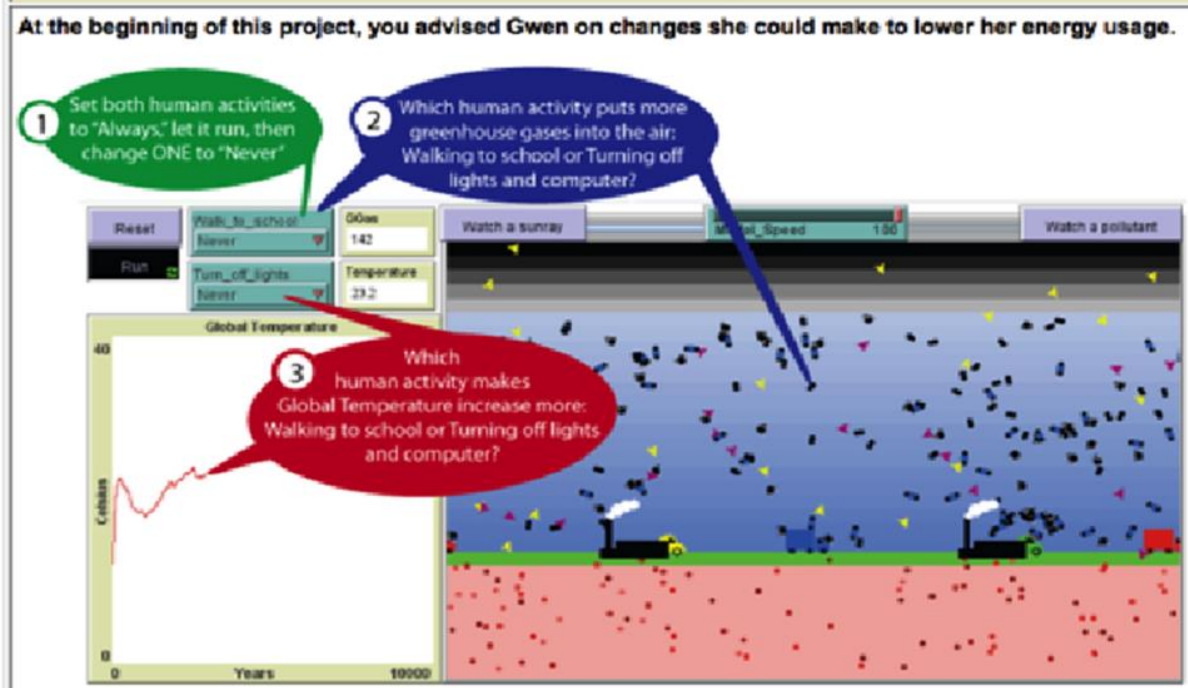

Now that you have learned how energy plays a role in the natural grcenhouse effect, use the model to find out bow human actions add so the greenhouse effect. Which factor do you think has the biggest effect on global temperature?
Figure 1. WISE Global Climate Change Experiments.

guiding students to both conduct experiments and critique experiments was more effective than guiding students to only conduct experiments (Chang \& Linn, in press).

For Global Climate Change, adding scaffolds that encouraged students to be systematic when exploring factors that might increase greenhouse gases was effective (Svihla \& Linn, 2011). One scaffold focused students on how individual sunrays behave when they enter Earth's atmosphere. Students can compare sunrays that are reflected to those that are absorbed and transformed into heat energy. These activities help 
students appreciate the role of energy transformations in climate change. These scaffolds help students interpret visualizations and achieve knowledge integration concerning greenhouse gases.

However, students often ignore conservation of matter when thinking about chemical reactions that produce greenhouse gases and therefore do not appreciate the source of these gases. In one study, students simply removed extra atoms when drawing the results of a chemical reaction (Chang, Quintana, \& Krajcik, 2013). This is consistent with students' views that greenhouse gases can easily be removed from the environment.

To help students understand how greenhouse gases are produced in combustion reactions, students are guided to explore combustion of methane and ethane to produce carbon dioxide and water (Rafferty, Gerard, McElhaney, \& Linn, 2013). Students illustrate combustion using the WISE Draw feature (Figure 2). This feature provides students with "stamps" for each atom (such as for oxygen, carbon, and hydrogen). Students must decide on the number of atoms to add to their drawings and arrange the atoms to show how they are grouped into molecules. The drawings enable students to articulate their ideas about chemical reactions and to use an alternative to the typical equation to represent their knowledge.

Using data about the spatial information in the drawings an algorithm was designed to identify both students' normative and non-normative ideas. Knowledge integration guidance was developed to help students distinguish between normative and nonnormative ideas (Rafferty, et al., 2013). Specifically, to anchor the guidance to students' prior knowledge a correct feature of the drawing was acknowledged, and then a question was presented to focus students on a conceptual difficulty. The guidance then prompted students to resolve this difficulty by reviewing a relevant activity seen previously in the unit and revising their drawing. We compared knowledge integration guidance to a more straightforward approach of highlighting errors and prescribing specific fixes. We found that knowledge integration guidance promoted a better understanding of the material.

Studies on the effectiveness of knowledge integration guidance illustrate the importance of coupling adding ideas to distinguishing ideas to create effective instruction. Students benefit from comparing their existing ideas to new ideas introduced in WISE and from developing criteria for selecting the most promising ideas. In Thermal Equilibrium, students were specifically guided to use experimental criteria to interpret the visualizations. For Global Climate Change, the situation was more complicated. Even when students conducted controlled experiments to isolate the contribution of gasoline combustion to climate

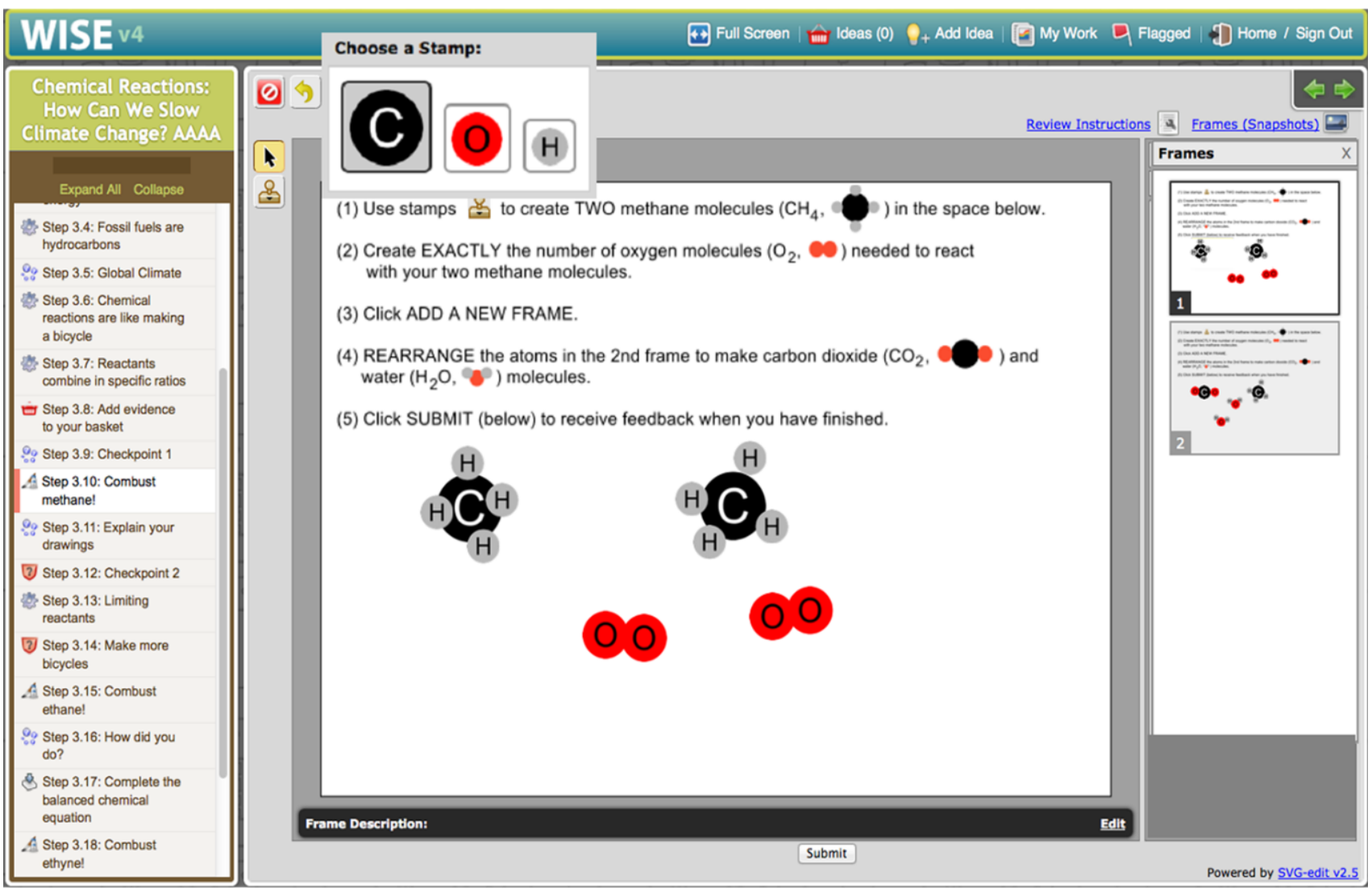

Figure 2. WISE Draw: Methane combustion. 
change they still often referred to the process as adding heat rather than accumulation of greenhouse gases. By combining activities involving chemical reactions that produce greenhouse gases (CO2) with activities concerning the role of greenhouse gases in climate change we are exploring ways to help students develop a coherent account of the role of greenhouse gases in global warming.

\section{Reflecting on ideas}

Reflecting on the repertoire of ideas to identify consistencies and open questions is essential for achieving durable scientific understanding (Collins \& Brown, 1998). Making predictions, adding ideas, and distinguishing among ideas is helpful. However, to form an integrated perspective students need to reflect on the evidence that generated their original ideas, the new evidence, and the connections among the ideas they have.

Reflection is typically achieved by generating and refining explanations for reasonably complex problems. The process of reflecting and refining reflections is an important step towards lifelong learning. These actions can stimulate a process of questioning one's own ideas and revisiting scientific issues when they arise in new contexts, such as news articles or public lectures. Lifelong learners become adept at sorting out their existing ideas and integrate them with new ideas in order to continue to build coherent understanding. By practicing reflection regularly, students can develop the ability to monitor their own progress and to recognize new connections as they arise. Recognizing and processing these connections is essential for building a coherent, cumulative understanding of science.

\section{WISE ASSESSMENTS AND GUIDANCE}

WISE embedded and end-of-unit assessments serve as both learning and evaluation activities. For example, students often write essays such as energy stories. In this form of assessment students describe a sequence of energy transfers and transformations for a complex phenomenon. This type of essay prompts students to reflect on their understanding of the phenomenon under investigation and to integrate this understanding with their broader understanding of energy. If students were given guidance that encouraged them to distinguish among their articulated ideas and ideas in the unit, the assessment could also be a learning opportunity.

Both Thermal Equilibrium and Global Climate Change feature energy stories where students explain energy transfer and transformation for everyday events. In Thermal Equilibrium, students write an essay about thermal equilibrium in a warm context: A metal spoon, a wooden spoon, and a plastic spoon are placed in hot water. After 15 seconds which spoon will feel hottest? Most students select the metal spoon but the evidence for their choice varies widely. Responses categorized according to the knowledge integration rubric are shown in Table 1.

Similarly, for Global Climate Change, students write an essay in response to the question: Burning coal to produce electricity has increased the carbon dioxide content of the atmosphere. What possible effect could the increased amount of carbon dioxide have on our planet?

This question encourages students to reflect on human activity and greenhouse gas accumulation. Initial answers include responses where students focus on the

Table 1. Knowledge integration rubric for scoring spoons question

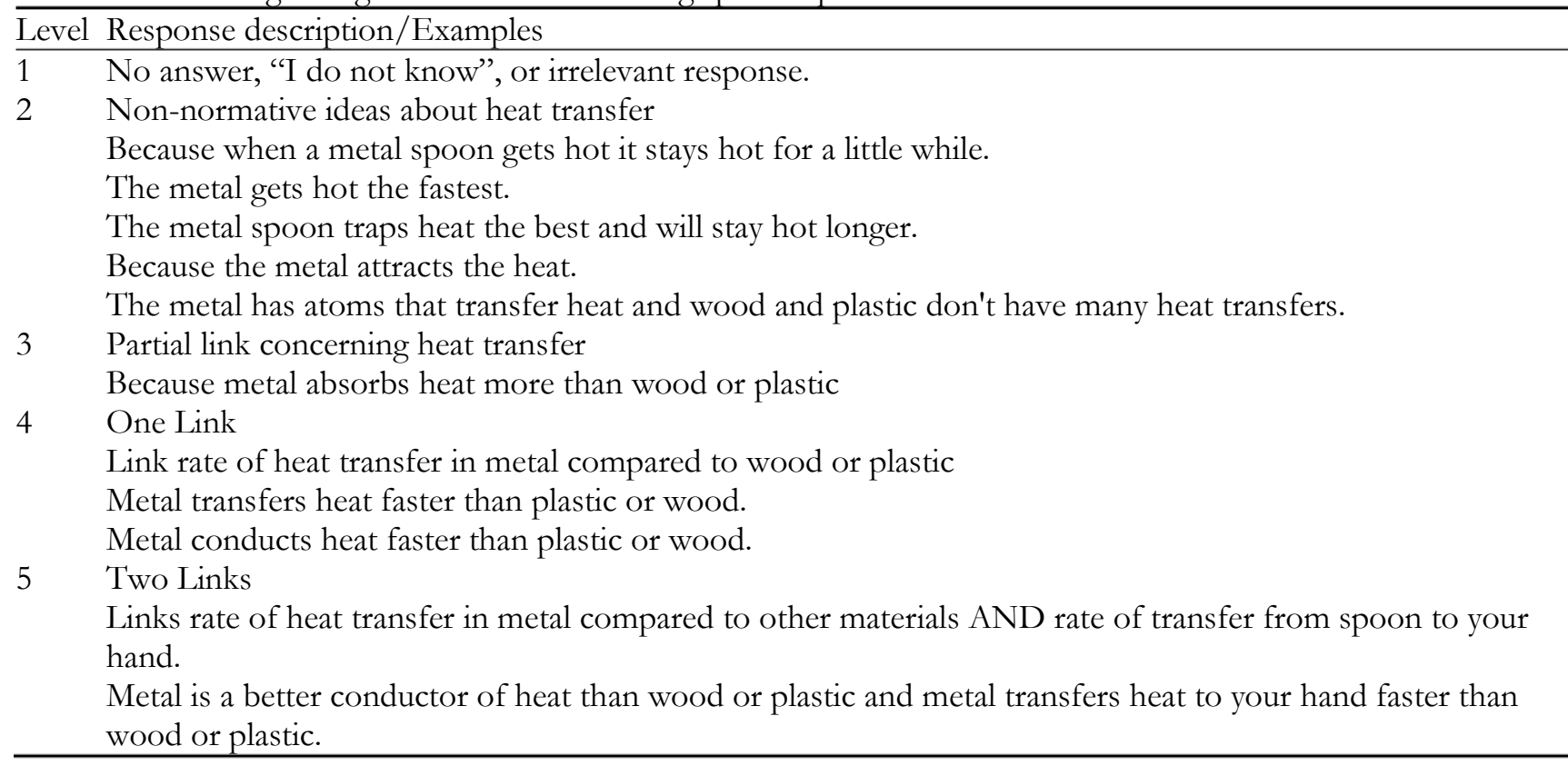


heat generated by burning coal or say something about ozone.

We have begun to explore ways to score these essays automatically and to use the scores to generate guidance. We have used ETS c-rater technology to automatically score student responses while they are working on the WISE unit (Liu et al., 2014). Students submit their answers and c-rater determines their knowledge integration score. Results show that automatically generated scores are about as accurate as scores generated by raters who receive a half-day of instruction. These scores can help teachers gauge progress of their students. They can be used by both teachers and WISE to provide guidance

Using WISE, we are exploring ways to use these scores to offer guidance aligned to student initial responses (Linn, Gerard, Ryoo, McElhaney, Liu, \& Rafferty, 2014). In a pilot study, we designed knowledge integration guidance to encourage distinguishing ideas. This guidance does not provide the right answer. Rather, consistent with the knowledge integration framework, it acknowledges student progress, identifies a weakness or missing idea, suggests a way to locate the missing information, and encourages the student to rewrite the essay. Teachers reviewing this guidance found it promising. For example one participating teachers wrote in a summer training session that, "I liked when [a researcher gave knowledge integration guidance]. It was great for me to look at what her feedback was [because] it gave me great guidance on what would be good feedback. Really awesome to have that as guideline."

Our pilot results showed that this form of guidance on embedded assessments could help student pairs distinguish ideas and revise their responses. For example, for the coal item, one student pair (Sasha \& Chris) answered by referring to ozone, "Burning coal would produce carbon dioxide which become greenhouse gases, which would break parts of the ozone layer." Their response was assigned a c-rater score of 2 , indicating that the response has non-normative scientific ideas.

Using the knowledge integration approach, guidance assigned based on this score was: "To improve your response return to [an activity where it is possible to add carbon dioxide and test the impact on global temperature] to find out how increased carbon dioxide in the atmosphere affects the global temperature." Sasha and Chris revised their response to say, "Burning coal has increased the amount of carbon dioxide in the atmosphere. Carbon dioxide can increase the temperature of the climate." Considering that the guidance did not explicitly contradict the ideas about ozone, the change in response suggests that Sasha and Chris were able to add a new idea and distinguish it from the previous idea about ozone.
Another student group, Erin and Sam, initially earned a 3, reflecting some normative ideas but superficial connections among ideas: "It could warm up the earth because the more carbon dioxide will make the earth warmer." The assigned guidance encouraged further reflection on how carbon dioxide would make the Earth warmer, "To improve your response return to[an activity where it is possible to explore how CO2 keeps the infrared radiation in the atmosphere] to find out how carbon dioxide in the atmosphere affects the global temperature by interacting with energy released by the surface of the Earth."

Erin and Sam revised their response to say, "Carbon dioxide is a greenhouse gas, and green house gases make the earth warmer. They make the earth warmer because they keep the infrared radiation in the atmosphere, which heats up the earth." This response earned a 4 because it correctly connects ideas about greenhouse gases resulting in warming with the mechanism for why this warming occurs. For both student groups, knowledge integration guidance encouraged them to incorporate one new normative idea into their explanation.

As these examples indicate, knowledge integration guidance could help students by directing them back to relevant material they have already reviewed and encouraging them to incorporate the ideas into their explanations. We are exploring how knowledge integration guidance can be provided automatically and by teachers. In either case, knowledge integration guidance encourages students to analyze the material more closely and increase the precision of their responses.

\section{DISCUSSION}

Research comparing alternative designs for instruction has resulted in the knowledge integration framework. Ongoing research offers ways to extend this framework by taking advantage of automated scoring of student work. Preliminary results show that guidance designed following the knowledge integration framework is more effective than guidance that emphasizes the right answer. These findings are consistent with the potential of the knowledge integration framework to promote lifelong inquiry learning capabilities.

Guidance that asks students to improve their responses by reviewing evidence or reflecting on their ideas engages them in distinguishing among their ideas. This can help students develop strategies for dealing with new dilemmas in the future. For example, when students encounter a new perspective they might be more likely to test the new idea against their other views, rather than just adding it to the mix, or accepting it without much thought. To promote lifelong learning 
it is important to transfer responsibility for knowledge integration from the instruction to the student. Instilling the practices of testing ideas against evidence and reflecting on alternatives can prepare students to make sense of new dilemmas.

WISE is uniquely tailored to help educators design curriculum focused on knowledge integration. WISE has a large number of features such as WISE Draw that can support the process of knowledge integration. WISE tools can scaffold learners by using automated scores to generate knowledge integration guidance. These tools also support teachers by allowing them to monitor student progress and provide their own guidance to individual students. Existing WISE projects address a wide range of science, mathematics, and engineering topics, including: plate tectonics, photosynthesis, genetics, density, and graphing of motion. New topics are regularly added.

WISE has a powerful authoring language that is very easy to use. Authors can create new units as well as customize existing units to new contexts. Evidence shows that when teachers customize their units based on the responses of their students, the next cohort of students performs better (Gerard, Varma, Corliss, \& Linn, 2011).

Between 2011 and 2014 over 10,000 teachers and 80,000 students joined the WISE community based in California. Additional teachers and students are using instances of WISE set up in Taiwan (http://twise.nknu.edu.tw:8888/webapp/index.html) and other locations. Researchers around the world are also using WISE to conduct systematic investigations by varying conditions to answer important questions about the most effective way to design inquiry instruction (e.g., Raes, Schellens, De Wever, \& Vanderhoven, 2012; Williams, DeBarger, Montgomery, Zhou, \& Tate, 2012).

\section{Acknowledgements}

This material is based upon work supported, in part, by the National Science Foundation under Grants DRL1119670: Continuous Learning and Automated Scoring in Science (CLASS); DRL-0918743: Visualizing to Integrate Science Understanding for All Learners (VISUAL); and Cumulative Learning using Embedded Assessment Results (CLEAR) DRL-0822388. Any opinions, findings, and conclusions or recommendations expressed in this material are those of the author(s) and do not necessarily reflect the views of the National Science Foundation.

\section{REFERENCES}

Andersson, B., \& Wallin, A. (2000). Students' understanding of the greenhouse effect, societal consequences of reducing $\mathrm{CO} 2$ emissions and why ozone layer depletion is a problem. Journal of Research in Science Teaching, 37(10),1096-1111.

Boyes, E., \& Stanisstreet, M. (1997). Children's models of understanding of two major global environmental issues (ozone layer and greenhouse effect). Research in Science and Technological Education, 15(1), 19-28.

Chang, H.-Y., \& Linn, M. C. (2013). Scaffolding learning from molecular visualizations. Journal of Research in Science Teaching. doi: 10.1002/tea.21089.

Chang, H-Y, Quintana, C., \& Krajcik, J. (2013) Using Drawing Technology to Assess Students' Visualizations of Chemical Reaction Processes. Journal of Science Education and Technology DOI: 10.1007/s10956-0139468-2

Chiu, J. L., \& Linn, M. C. (2013). Supporting knowledge integration in chemistry with a visualization-enhanced inquiry unit. Journal of Science Education and Technology. doi:10.1007/s10956-013-9449-5

Collins, A., \& Brown, J. S. (1988). The computer as a tool for learning through reflection. In H. Mandl and Lesgold (Eds.), Learning issues for intelligent tutoring systems. (pp. 118). New York: Springer-Verlag.

de Jong, T., Linn, M. C., \& Zacharia, Z. C. (2013). Physical and Virtual Laboratories in Science and Engineering Education. Science, 340(6130), 305-308

Donnelly, D. F., Linn, M. C., \& Ludvigsen, S. (2014). Impacts and Characteristics of Computer-Based Science Inquiry Learning Environments for Precollege Students. Review of Educational Research, 20(10), 1-37. doi: 10.3102/0034654314546954

Gerard, L. F., Varma, K., Corliss, S. C., \& Linn, M. C. (2011). Professional Development for Technology-Enhanced Inquiry Science. Review of Educational Research, 81(3), 408448. DOI: 10.3102/0034654311415121

Linn, M. C., \& Eylon, B.-S. (2011). Science Learning and Instruction: Taking Advantage of Technology to Promote Knowledge Integration. New York: Routledge.

Linn, M. C., Gerard, L. F., Ryoo, K., McElhaney, K., Liu, L., \& Rafferty, A. N. (2014). Computer-guided inquiry to Improve Science Learning. Science, 344, 155-156. doi: 10.1126/science. 1245980

Linn, M. C. \& Songer N. B. (1991). Teaching thermodynamics to middle school students: What are appropriate cognitive demands? Journal of Research in Science Teaching, 28, 885-918.

Liu, O. L., Brew, C., Blackmore, J., Gerard, L. F., Madhok, J., \& Linn, M. C. (2014). Automated Scoring in Inquiry Science Assessment: Application of c-rater. Educational Measurement: Issues and Practice. doi: 10.1111/emip.12028

Mayer, R. E., Dow, G., \& Mayer, S. (2003). Multimedia learning in an interactive self-explaining environment: What works in the design of agent-based microworlds? Journal of Educational Psychology, 95, 806-813.

McElhaney, K.W. \& Linn, M.C. (2011). Investigations of a Complex, Realistic Task: Intentional, Unsystematic, and Exhaustive Experimenters. Journal of Research in Science Teaching, 48(7), 745-770.

Raes, A., Schellens, T., De Wever, B., \& Vanderhoven, E. (2012). Scaffolding information problem solving in web-based collaborative inquiry learning. Computers \& Education, 59(1), 82-94. 
Rafferty, A. N., Gerard, L. F., McElhaney, K., \& Linn, M. C. (2013). Automating Guidance for Students Chemistry Drawings. Paper presented at the Artificial Intelligence in Education 2013, University of Memphis.

Ryoo, K., \& Linn, M.C. (2012). Can dynamic visualizations improve middle school students' understanding of energy in photosynthesis? Journal of Research in Science Teaching, 49(2), 218-243.

Shepardson, D.P., Niyogi, D., Choi, S., \& Charusombat, U. (2009). Seventh grade students' conceptions of global warming and climate change. Environmental Education Research, 15(5), 549-570.

Slotta, J. D. \& Linn, M. C. (2009) WISE Science. New York: Teachers College Press.

Svihla, V., Linn, M. C. (2011). A Design-based approach to fostering understanding of global climate change. International Journal of Science Education, DOI:10.1080/09500693.09502011.09597453.

Varma, K. \& Linn, M. C. (2012). Using Interactive Technology to Support Students' Understanding of the Greenhouse Effect and Global Warming. Journal of Science Education and Technology. 21(4) DOI: 10.1007/s10956-011-9337-9.

Visintainer, T. and Linn, M.C. (Submitted). Sixth grade students' progress in understanding the mechanisms of global climate change. Journal of Science Education and Technology.

White, R., \& Gunstone, R. (1992). Probing understanding. New York: The Falmer Press.

Williams, M., DeBarger, A. H., Montgomery, B. L., Zhou, X., \& Tate, E. (2012). Exploring middle school students' conceptions of the relationship between genetic inheritance and cell division. Science Education, 96(1), 78103. doi:10.1002/sce. 20465.

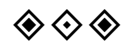

